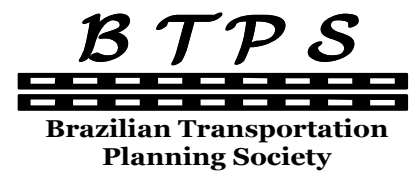

Journal of Transport Literature

Vol. 7, n. 2, pp. 97-123, Apr. 2013

Research Directory
JTL | RELIT

www.transport-literature.org

\title{
Acessibilidade na Região Amazônica através do transporte hidroviário
}

[Accessibility in the Amazon region through the water transportation]

\author{
Andréa Vaz Morgado, Licínio da Silva Portugal, Andréa Justino Ribeiro Mello* \\ Universidade Federal do Rio de Janeiro (UFRJ), Brazil, Universidade Federal do Rio de Janeiro (UFRJ), Brazil, \\ Centro Federal de Educação Tecnológica (CEFET/RJ), Brazil
}

Submitted 29 Feb 2012; received in revised form 15 Jun 2012; accepted 11 Jul 2012

\begin{abstract}
Resumo
O estudo dos padrões de acessibilidade pode contribuir, efetivamente, para o desenvolvimento sustentável e equitativo de determinadas regiões. Isso ocorre a partir da identificação, hierarquização e seleção de alternativas de investimentos mais adequadas para o setor de transportes dada a realidade local. Sendo assim, o presente artigo tem como principal proposta identificar os níveis de acessibilidade fornecidos pelo transporte hidroviário de passageiros em algumas das principais áreas que constituem a região amazônica, verificando-se as localidades com melhores condições de deslocamento e aquelas que necessitam de maior investimento. Considerando-se como fatores de impedância o tempo, a distância e a tarifa, foram calculados indicadores de acessibilidades para localidades específicas da região amazônica. Os municípios pesquisados foram classificados de acordo com cinco categorias de acessibilidade: excelente, boa, regular, ruim ou péssima. Dentre os resultados alcançados temse que os municípios mais próximos de Manaus apresentam excelentes ou boas condições de acessibilidade enquanto aqueles mais distantes encontram-se em situação de desvantagem, merecendo maior atenção do poder público.
\end{abstract}

Palavras-Chave: análise espacial, acessibilidade, transporte hidroviário de passageiros, Região Amazônica, desenvolvimento regional.

\begin{abstract}
The study of accessibility standards can effectively contribute to sustainable and equitable development of certain regions. This is based on the identification, prioritization and selection of investment alternatives most appropriate for the transport sector given the local situation. Therefore, this article has proposed o identify the of accessibility provided by the water transport of passengers on some key areas that form the Amazon region, verifying the locations with better movement and those that need more investment. Considering impedance factors such as time, distance and price, accessibility indicators were calculated for specific locations in the Amazon region. The cities surveyed were classified according to five categories as excellent, good, fair, poor or very poor accessibility. Among the results has been that municipalities closer to Manaus have excellent or good accessibility while those more distant are disadvantaged, deserving of greater attention of the public authority.
\end{abstract}

Key words: spatial analysis, accessibility, passenger water transportation, Amazon region, regional development.

*Email: andreajribeiro@yahoo.com.br.

\section{Recommended Citation}

Morgado, A. V., Portugal, L. S. and Mello, A. J. R. (2013) Acessibilidade na Região Amazônica através do transporte hidroviário . Journal of Transport Literature, vol. 7, n. 2, pp. 97-123.

- JTL/RELIT is a fully electronic, peer-reviewed, open access, international journal focused on emerging transport markets and published by BPTS - Brazilian Transport Planning Society. Website www.transport-literature.org. ISSN 2238-1031. 


\section{Introdução}

A região Amazônica apresenta grande extensão e é objeto de enormes pressões para a apropriação de seus recursos naturais e para a sua ocupação, que inclusive ocorre de maneira desorganizada e com desequilíbrios socioeconômicos. O setor de transportes, baseado fundamentalmente na modalidade hidroviária, assume um papel de relevo, seja ao buscar atender os fluxos de pessoas e cargas derivados desta ocupação, seja por sua infraestrutura poder influenciar a forma e a qualidade deste desenvolvimento. Neste contexto, destaca-se a necessidade de um planejamento apropriado do sistema de transportes e da acessibilidade por ele fornecida a fim de contribuir para um desenvolvimento sustentável e mais equitativo.

Entende-se que o planejamento apropriado do sistema de transportes, atendendo as demandas existentes por meio de projetos de investimento em infraestrutura, aumenta as chances de inserção da população ribeirinha na dinâmica econômica vigente. Dessa forma, pode-se dizer que as implicações sociais e comportamentais dos transportes extrapolam a questão do deslocamento em si. Ou seja, características de acessibilidade e de mobilidade acarretam maior ou menor exclusão (inclusão) das pessoas em atividades disponíveis em determinadas localidades.

O transporte, de acordo com o exposto, é um dos elos fundamentais da vida em sociedade, pois é a partir dele que as pessoas podem se deslocar e participar das diversas atividades de que desejam. Na perspectiva de Calheiros (2010), na Amazônia, em decorrência das condições hidrográficas únicas ali existentes, o transporte fluvial é a economia e a vida social. O emprego, quase que exclusivo, das embarcações como meio de transporte determinou que a grande maioria dos núcleos urbanos se formasse nas margens dos rios.

A oferta desse transporte é uma parte bastante relevante do próprio desenvolvimento urbano da Região, envolvendo, dentre outros elementos, a frota de embarcações e as linhas existentes, a regularidade do serviço, as condições de embarque e desembarque, de viagem dentro das embarcações assim como de navegabilidade.

Criar compatibilidade entre a oferta de transportes e a sua demanda é uma forma de gerar acessibilidade às pessoas, impactando diretamente sobre os usuários do sistema e 
indiretamente, sobre a sociedade como um todo. Nesse aspecto, enquanto a incompatibilidade pode contribuir para a exclusão social de residentes de determinadas localidades, a compatibilidade, ao promover a acessibilidade, aumenta a inclusão social.

Estudar os padrões de acessibilidade existentes em determinadas localidades, segundo uma concepção abrangente e comprometida com o desenvolvimento integrado e a minimização das desigualdades, é uma das maneiras de se contribuir com a compatibilização entre a oferta e a demanda de transportes.

Esse debate em torno da interface entre exclusão social e transporte é algo relativamente novo, porém tem sido alvo de interesse crescente tanto no meio acadêmico quanto no âmbito dos planejadores de transporte desde fins dos anos 90, como apontam Delbosc e Currie (2010), Preston e Rajé (2007) e Cardoso (2007), dentre outros.

Esse levantamento das condições de acessibilidade torna possível a identificação, hierarquização e a seleção das alternativas de investimentos mais adequadas para o setor, viabilizando o aprimoramento das condições de deslocamento para a população residente nas localidades menos atendidas pelo sistema de transportes. Ou seja, criando-se condições para a inserção dessas pessoas na dinâmica econômica e social vigente.

Sua relevância está associada não só à importância do uso racional dos recursos públicos, mas também à grande representatividade do transporte fluvial anual de passageiros na Região Amazônica. Segundo o Ministério do Meio Ambiente (2006) esse quantitativo supera o total de 350 mil pessoas. Calheiros (2010) destaca que, por se tratar de uma população de baixa renda e com importantes problemas sociais, muitas vezes essas viagens são realizadas em condições precárias de segurança e conforto.

Portanto, apoiar o alcance de uma nova realidade, visando tornar mais ágil a implantação de estratégias que facilitem, através de intervenções na infraestrutura de transportes, a existência de um ambiente mais equitativo em termos de acessibilidade, consiste na principal motivação do presente estudo.

Para tal, se faz necessária a análise espacial da oferta de transportes e da acessibilidade por ela gerada em função das impedâncias existentes entre as diferentes áreas do território Amazônico. Sabe-se que a acessibilidade encontrada tende a ser maior quanto menores forem 
os obstáculos enfrentados para a realização dos deslocamentos. Assim, o tempo de percurso, tanto quanto a distância a ser percorrida e/ou o custo da viagem podem se configurar como impedâncias. Por isso, esses três fatores foram considerados no método empregado para calcular a acessibilidade de cada área estudada. Percebendo-se a necessidade de se considerar também algum elemento representativo da situação socioeconômica e de ocupação de cada município estudado, incluiu-se na pesquisa dados populacionais.

Nesse sentido, o procedimento adotado incluiu a seleção dos indicadores mais apropriados; o cálculo desses mesmos indicadores para cada município; a classificação de cada um segundo os padrões de acessibilidade encontrados; e, finalmente a análise dos resultados, determinando-se o grau de integração ou desarticulação existente entre as áreas que constituem a Região Amazônica, destacando-se aquelas que se encontram em condições mais críticas.

Na etapa de classificação das localidades segundo os padrões de acessibilidade encontrados, pode-se evidenciar que não há uma configuração equitativa da região estudada, havendo melhores condições de deslocamento para as localidades mais próximas à Manaus, enquanto as localidades mais distantes enfrentam maiores obstáculos para a realização de deslocamentos diversos, evidenciando-se nesses casos maior necessidade de intervenção do poder público através de investimentos de infraestrutura.

Para tratar tais questões, além dessa seção introdutória, o presente trabalho se divide da seguinte forma: na Seção 1 são apresentadas as peculiaridades do transporte hidroviário urbano. Na Subseção 1.1 há uma abordagem sobre o transporte hidroviário de passageiros no Brasil e no mundo. A Seção 2 insere a temática da navegabilidade da Região Amazônica. Na Seção 3 são abordados os indicadores de acessibilidade. A Seção 4 apresenta em detalhes o procedimento de pesquisa adotado para o desenvolvimento do presente trabalho. A apresentação dos resultados ocorre na Seção 5 e, por fim, na sequência, estão a conclusão e as referências. 


\section{O sistema de transporte hidroviário}

Assim como os sistemas de transporte aeroviário, ferroviário e rodoviário, o sistema hidroviário possui componentes próprios que influenciam na eficiência de suas operações. Dentre esses componentes estão as hidrovias, as embarcações e os terminais.

As formas de navegação existentes, de acordo com a Lei $n^{0}$ 9.432/1997, que dispõe sobre a ordenação do transporte hidroviário, se dividem em cinco tipos: a de apoio portuário, a de apoio marítimo, a de cabotagem, a interior e a de longo curso.

As navegações de apoio portuário e de apoio marítimo atuam como atividades de suporte. A navegação de cabotagem corresponde ao deslocamento entre portos ou pontos do território brasileiro por meio da via marítima ou entre esta e as vias navegáveis interiores; a navegação interior é realizada em hidrovias interiores, em percurso nacional ou internacional e por fim, a navegação de longo curso, se realiza entre portos brasileiros e estrangeiros.

Considerando-se que o presente artigo se propõe a abordar o transporte hidroviário na Região Amazônica, a forma de navegação privilegiada no decorrer da pesquisa é a navegação interior em território nacional, por meio dos rios pertencentes às Bacias Hidrográficas Amazônica e do Tocantins.

De acordo com Schneider (2000), a navegação interior pode ocorrer através de hidrovias naturais ou artificiais, no interior do continente, especialmente rios e canais. As hidrovias que atendem às condições de navegação, possibilitando o trânsito de embarcações de porte, são denominadas vias navegáveis interiores. Além de condições próprias, para que uma hidrovia seja segura à navegação, tanto para as embarcações como para cargas, passageiros e/ou tripulantes, há necessidade de seu adequado balizamento e sinalização.

O potencial de navegação característico de cada hidrovia depende de diversos fatores, e sua combinação pode limitar ou ampliar as condições de navegabilidade, assim como definir as embarcações-tipo, no que tange à sua dimensão e à sua capacidade de transporte, que podem usufruir de seu potencial.

Os sistemas de navegação existentes na Amazônia, segundo o Caderno de Recursos Hídricos da ANA (2005), podem ser classificados de acordo com a capacidade de carga e de 
navegabilidade entre: embarcações rústicas, embarcações de linha, comboios de balsas, comboios com tecnologia mais avançada e navios.

As embarcações rústicas são formadas por canoas a remo ou pequenas embarcações voadeiras) operadas por seus proprietários para o transporte de passageiros e de pequenas cargas consistem no único meio de acesso a comunidades ou casas isoladas localizadas na beira de igapós ou rios pequenos. As embarcações de linha transportam passageiros e distribuem cargas ao longo de toda a malha hidroviária da região, com barcos maiores, conhecidos por 'batelão' ou 'recreio'. Os comboios de balsas apresentam diferentes tamanhos, potência e calado para atender às mais diversas condições de navegabilidade dos rios e são utilizados para o transporte exclusivo de cargas. As balsas são rebocadas por barcos empurradores ou puxadores. Os comboios com tecnologia mais avançada dispensam o uso de guinchos, empilhadeiras e equipamentos e atendem, quase exclusivamente ao distrito industrial da Zona Franca de Manaus. Os navios, por vezes de porte oceânico, são especializados no transporte de minérios, mas fazem também o transporte de contêineres. Devido ao seu porte, estão limitados aos maiores rios da região.

De acordo com a Marinha do Brasil ${ }^{1}$, há características gerais desejáveis para qualquer tipo de embarcação fluvial: pequeno calado, compatível com a mínima lâmina d’água normalmente encontrada na hidrovia; dimensões adequadas aos raios de curvatura das curvas da hidrovia; proteção para os apêndices do casco (lemes, hélices, pés-de-galinha, etc.); boas características de manobra; estabilidade dinâmica para guinadas bruscas; ampla visibilidade do passadiço; comando das máquinas no passadiço; recursos para desencalhe por meios próprios; capacidade adequada de armazenagem de combustível e recurso para tratamento da água do rio; disponibilidade de radar com grande poder de discriminação em distância; disponibilidade de holofote com foco de luz direcional, concentrado, sem formação de halo; e disponibilidade de ecobatímetro, capaz de determinar profundidades muito pequenas e indicar continuamente o perfil do fundo.

Dadas as características das vias e das embarcações que compõem o sistema de transporte hidroviário, Andrade et al (2003) destacam a necessidade de um eficiente sistema alimentador/distribuidor devido a quase inexistência da acessibilidade porta a porta.

\footnotetext{
1 Documento da Marinha do Brasil (sem data), "Navegação Fluvial". Disponível em www.mar.mil.br/dhn/bhmn/download/cap-40.pdf. Data da consulta: 02/06/2010
} 
Dessa forma, conforme menciona Souza (2009), é fundamental considerar-se a necessidade de transbordo de um modo de transporte para outro para que o transporte hidroviário urbano seja de fato uma alternativa modal para uma área urbana. O que requer terminais de integração com localização adequada para o embarque e desembarque de passageiros de maneira eficiente e eficaz.

\subsection{O transporte hidroviário de passageiros no Brasil e no mundo}

$\mathrm{Na}$ atualidade, constata-se que preocupações relativas ao desenvolvimento econômico sustentável têm motivado a busca por alternativas aos transportes individuais motorizados. Nesse contexto, o sistema hidroviário de transporte de passageiros se mostra como uma opção promissora que tem mobilizado esforços para o desenvolvimento de novos projetos de investimento em diversos países do mundo, inclusive no Brasil.

Apresenta-se, a seguir, uma breve caracterização do transporte hidroviário de passageiros no mundo tendo-se como principal referência o trabalho de pesquisa desenvolvido por Souza (2009).

No continente asiático, a China se destaca com um dos maiores sistemas de canais interiores do mundo, alcançando cerca de 110.000 quilômetros. Contrariamente a outros países, o desenvolvimento de seu sistema de transportes se deu de forma concomitante em todos os modais, incluindo investimentos significativos na infraestrutura de terminais de integração para o transporte de passageiros, atingindo mais de 50 linhas em Hong Kong, por exemplo.

No tocante ao Japão, houve a adoção de um sistema de transporte hidroviário especialmente com a finalidade de reduzir o congestionamento do tráfego em áreas urbanas do centro das grandes cidades, chegando-se a mais de 80 ligações no transporte hidroviário. Na baia de Tóquio, por exemplo, o Rio Edo foi saneado e atualmente está sendo utilizado por diversos tipos de embarcações.

Bangladesh também apresenta um sistema de transporte fluvial interior muito significativo e, em Dubai, na Índia, a demanda aponta para uma tendência de expansão considerável (segundo o site www.skyscrapercity.com, espera-se transportar cerca de cinco milhões de passageiros por ano nos próximos anos) por meio do transporte hidroviário. 
Sidnei, na Austrália, possui um número superior a 50 linhas de transporte hidroviário e tem um dos sistemas mais perfeitos em termos de intermodalidade na área de transportes, pois a partir do terminal Circular Quay concentram-se o sistema ferroviário, metroferroviário, rodoviário e hidroviário.

Na Europa também são encontradas regiões nas quais o transporte hidroviário apresenta um dos principais elementos para sua expansão, as hidrovias. Veneza, cidade cercada pela água, cujo transporte público é garantido por uma rede de canais, possui diversas linhas. Cada linha atendida pelo ônibus hidroviário apresenta finalidades próprias, desde o atendimento de necessidades específicas de seus habitantes até a garantia de mobilidade de um grande número de visitantes.

No Reino Unido há outra experiência da utilização de ônibus hidroviário, na Baia de Cardiff, onde o ônibus hidroviário está disponível tanto para o turismo e viagens ao centro como para serviços exclusivos, por fretamento, para muitas escolas e universidades.

Com especial atenção para a navegabilidade dos rios Labe e Pardubice, o Ministério dos Transportes da República Tcheca estabeleceu prioridades para renovação e desenvolvimento de vias fluviais para o alcance de melhorias nos parâmetros de navegação. Ainda com relação a esse país, pode-se dizer que o transporte em via fluvial interior em distâncias curtas é pouco significativo.

$\mathrm{Na}$ Turquia, se destacam as cidades de Ancara, por possuir mais de 80 ligações hidroviárias, e a cidade de Istambul, por ter um sistema de transporte completamente integrado ao sistema hidroviário.

Desde fins do século XX, segundo Marchal (1999, apud Souza, 2009), a União Européia vem repensando a concepção do transporte hidroviário, através do projeto CATRIV. Novos conceitos de navios foram avaliados com base em critérios técnicos, econômicos e ambientais, além de cenários diversos, com o intuito de integrar o transporte hidroviário aos sistemas de transportes públicos atuais.

Nesse contexto, os canais passaram a atrair projetos de infraestrutura, envolvendo desde os canais já existentes até a construção de novos canais. Manchester é um exemplo, com a 
construção de um novo canal para o transporte de passageiros do centro comercial para fora da cidade no parque de Trafford, 100 anos após a construção do primeiro canal.

De acordo com Neves (s.d.), de uma forma geral, os governos de diversos países europeus como Noruega, Inglaterra, Irlanda, Grécia e Itália, dentre outros, vêm incentivando o transporte hidroviário urbano de passageiros.

No continente americano, por outro lado, também há movimentos que apontam para novas perspectivas no transporte hidroviário. Na Flórida, Estados Unidos, por exemplo, em novembro de 2001 iniciou-se uma rota fixa experimental de serviços em ônibus hidroviário, conectando praias e hotéis e o centro da cidade de Fort Lauderdale. O Canadá apresenta um dos sistemas mais importantes dentro do planejamento de transporte com uma intermodalidade muito positiva, conforme destaca Souza (2009). O Alasca apresenta um conjunto de 4 linhas e de 4 ligações.

De acordo com Godoy e Vieira (2004), no Brasil, por iniciativa do governo federal, algumas obras beneficiando a navegação interior foram ou estão sendo realizadas, em consonância com os programas de investimento do setor de transportes, cabendo destacar as da bacia dos rios Tietê e Paraná e as dos rios Jacuí e Taquarí (no estado do Rio Grande do Sul), além de melhoramentos diversos, executados em rios de navegação em corrente livre. Essa iniciativa configura-se como um elemento importante num cenário de crescimento do transporte hidroviário urbano de passageiros no país.

Segundo Alves (2007), na jurisdição da ANTAQ, a navegação interior no Brasil ocorre no transporte longitudinal (interestadual e internacional) e nas travessias em diretriz de rodovias federais. A distribuição geográfica das 138 travessias cadastradas se dá da seguinte forma: 16 no sudeste; 18 no centro-oeste; 29 no nordeste; 29 no norte e 46 no sul.

Na região Amazônica, especificamente, desde 1994, de acordo com o estudo diagnóstico dos serviços de transportes fluvial, terrestre e aéreo da região, desenvolvido pela Agência de Desenvolvimento da Amazônia (ADA), há instituições públicas - UFPA, FADESP, AHIMOR, FINEP e CAPES - que têm atuado e/ou colaborado com o setor de transporte fluvial. Ainda de acordo com esse estudo, os principais eixos fluviais da região estão entre: 
Belém e Macapá; Belém e Manaus; Belém e Santarém; Manaus e Porto Velho; Manaus e Santarém; Santarém e Macapá; Santarém e Itaituba.

Identificou-se que nesses principais eixos há uma grande movimentação de cargas e passageiros intermunicipais e interestaduais distribuídos em diversas rotas fluviais, principalmente de média e longa distâncias. As diversas linhas apresentam origens e destinos diferentes, havendo um convívio de linhas regulares e de barqueiros.

A importância dessa modalidade de transporte de passageiros se dá em função do posicionamento dos núcleos populacionais situados à margem dos rios sem nenhuma alternativa. Em Manaus, observa-se que as ligações são tradicionais e a hidrovia exerce um papel fundamental idêntico ao sistema rodoviário de outras cidades, devido à capilaridade dos rios da bacia amazônica.

\section{Navegabilidade da Região Amazônica}

Cada rio que pertence à Rede Hidroviária Brasileira oferece condições de navegabilidade bem diferentes, de acordo com o Caderno de Recursos Hídricos desenvolvido pela ANA (2005), que apresenta as características das hidrovias de interior. Essas diferenças envolvem aspectos como o calado, a largura da rota de navegação, os raios das curvas, a presença de corredeiras, as cachoeiras, barragens e eclusas, bem como as variações decorrentes do ciclo hidrológico. Tais características refletem as condições da infraestrutura de transporte hidroviário. Ainda segundo este Caderno, caso fossem incluídos os trechos de rios navegáveis apenas nas cheias e os potencialmente navegáveis, ou seja, aqueles que podem adquirir boas condições de navegabilidade através de obras de melhorias, a rede hidroviária brasileira poderia ultrapassar a extensão de $40.000 \mathrm{~km}$.

É importante ressaltar que o estudo de acessibilidade da rede hidroviária depende das características de navegabilidade que contribuirão para estabelecer as peculiaridades de cada área da região.

A região hidrográfica que abrange os municípios deste estudo compreende: as bacias Amazônica e do Tocantins. A bacia Amazônica corresponde a 59\% da rede hidrográfica 
brasileira, com uma extensão de $18.300 \mathrm{Km}$, enquanto a bacia do Tocantins corresponde a $13 \%$ dessa mesma rede, com $3.500 \mathrm{Km}$ de extensão.

Tabela 1 - Condições de navegação dos rios que ligam os municípios em estudo²

\begin{tabular}{|c|c|}
\hline Hidrovias & Condições de navegação \\
\hline Amazonas & $\begin{array}{l}\text { Possibilita a navegação de longo curso e cabotagem em toda sua } \\
\text { extensão. Liga as cidades de Manaus e Belém, além de Santarém e } \\
\text { Macapá. É navegável na extensão de } 1.650 \mathrm{Km} \text {. }\end{array}$ \\
\hline Tapajós-Teles & $\begin{array}{l}\text { Navegável somente do porto de Santarém, na foz do rio Tapajós } \\
\text { quando deságua no rio Amazonas, até as corredeiras de São Luís do } \\
\text { Tapajós, na cidade da Itaituba (PA), com a extensão de } 345 \mathrm{Km} \text {. }\end{array}$ \\
\hline Jarí & $\begin{array}{l}\text { Navegável no trecho desde sua foz até a Cachoeira de Santo Antônio, } \\
\text { no município de Laranjal do Jari (AP), com a extensão de } 110 \mathrm{Km} \text {. }\end{array}$ \\
\hline Solimões & $\begin{array}{l}\text { Francamente navegável de sua foz até a cidade de Coari, com a } \\
\text { extensão de } 1.620 \mathrm{Km} \text {. }\end{array}$ \\
\hline Madeira & $\begin{array}{l}\text { Permite navegação de grandes comboios com até } 18.000 \text { t mesmo na } \\
\text { época de estiagem, com a extensão de } 1.060 \mathrm{Km} \text {. Faz ligação entre } \\
\text { Porto Velho, Humaitá e Itacoatiara. }\end{array}$ \\
\hline Negro & $\begin{array}{l}\text { É navegável em terras brasileiras na extensão de } 1.070 \mathrm{~km} \mathrm{e} \mathrm{a} \\
\text { montante é navegável além da fronteira com a Venezuela, sendo que } \\
\text { no período de águas baixas existe restrição de profundidade acima da } \\
\text { cidade de São Gabriel da Cachoeira (AM). }\end{array}$ \\
\hline Branco & $\begin{array}{l}\text { É navegável até a confluência dos rios Uraricoera e Tacutu, logo a } \\
\text { montante da cidade de Boa Vista (RR). Nesse trecho, os } 14 \mathrm{~km} \text { das } \\
\text { corredeiras de Bem-Querer, situadas a montante da cidade de } \\
\text { Caracaraí (RR), constituem o principal impedimento à navegação } \\
\text { regular. Nos cerca de } 440 \mathrm{~km} \text { do trecho entre a foz e as corredeiras, a } \\
\text { navegação no rio Branco pode ser realizada por embarcações maiores. }\end{array}$ \\
\hline Acre & $\begin{array}{l}\text { É navegável no trecho de } 635 \mathrm{~km} \text {, de sua foz, em Boca do Acre, até a } \\
\text { cidade de Brasiléia (AC), passando por Rio Branco (AC). No trecho } \\
\text { entre Rio Branco e Brasiléia a navegação só é possível durante as } \\
\text { cheias. Na cidade de Rio Branco, existem pontes que dificultam a } \\
\text { passagem de embarcações. }\end{array}$ \\
\hline Juruá & $\begin{array}{l}\text { É navegável desde sua foz, na margem direita do rio Solimões, até a } \\
\text { cidade de Cruzeiro do Sul (AC), na extensão } 3.128 \mathrm{~km} \text {. Durante a } \\
\text { época das águas altas, pode ainda ser navegado até a fronteira com o } \\
\text { Peru, passando pela cidade de Marechal Thaumaturgo (AC). Sua } \\
\text { grande sinuosidade é um empecilho. }\end{array}$ \\
\hline
\end{tabular}

\footnotetext{
${ }^{2}$ Fonte: elaboração própria.
} 
A Região Hidrográfica Amazônica compreende as seguintes hidrovias: do Amazonas, do Solimões, do Madeira, do Negro e Branco, do Purus, do Juruá, do Tapajós, do Trombetas, do Xingu, do Marajó e de muitos outros rios navegáveis e de menor porte. Como os rios da região Amazônica apresentam grande diversidade nas condições de navegação, a Tabela 1 apresenta uma síntese das informações obtidas do Caderno de Recursos Hídricos (ANA, 2005).

Tais bacias são de competência das seguintes administrações hidroviárias: da Hidrovia da Amazônia Oriental - AHIMOR (compreendendo os estados do Pará e Amapá), da Hidrovia da Amazônia Ocidental - AHIMOC (compreendendo os estados de Roraima, Amazonas, Acre e Rondônia) e da Hidrovia do Tocantins/ Araguaia (AHITAR). Segundo a ANA (2005), estas administrações são órgãos responsáveis por promover e desenvolver as atividades de execução, acompanhamento e fiscalização de estudos, obras e serviços de hidrovias, dos portos fluviais e lacustres que lhe venham a ser atribuídos pelo Departamento de Infraestrutura Aquaviária.

Cabe destacar que apesar de os rios Tocantins, Araguaia e das Mortes atravessarem as regiões Centro-Oeste e Amazônica, estes rios não interligam os municípios e/ou capitais selecionados para o estudo de acessibilidade. Somente a hidrovia do Guamá-Capim está localizada na região leste do Pará, interligando regiões do interior do Estado até Belém e sendo navegável durante todo ano.

\section{Indicadores de acessibilidade}

Na perspectiva de Halden (2002), os indicadores de acessibilidade podem ser classificados como medidas de oportunidade ou medidas de valor. As medidas de oportunidade envolvem uma medida de contorno e tratam do número de oportunidades disponíveis dentro de um intervalo de tempo ou de custo pré-definido, enquanto as medidas de valor estabelecem valores de tempo e/ou custo para a acessibilidade de determinada(s) localidade(s).

Envolvendo medidas exclusivas de tempo, Luís (2002) pesquisou a acessibilidade temporal existente entre as Ilhas Canárias. Para tal, foram calculados diversos tipos de tempo envolvidos no tempo total gasto na viagem porta a porta da origem ao destino: aquele relativo 
à viagem terrestre até o terminal de embarque, o de checking-in, o de embarque, durante o percurso no mar, no desembarque e na retirada da bagagem. Ou seja, a acessibilidade de cada Ilha da região foi estabelecida em função da acessibilidade temporal, especificamente.

Bertolini et al (2005), com o intuito de contribuir com o desenvolvimento conceitual da acessibilidade sustentável, por meio da integração entre o planejamento de transportes e do uso do solo na Holanda, destacaram uma medida cumulativa de oportunidades, na qual poderiam ser utilizados o montante de habitantes, de emprego ou nós urbanos passíveis de serem alcançados a partir de um dado tempo de viagem.

$\mathrm{Na}$ escolha de indicadores de acessibilidade a serem utilizados para determinada finalidade, Geurs e Wee (2004) apontam para quatro componentes relevantes: o uso do solo, o sistema de transporte, o tempo e as características individuais, cada qual com seus elementos próprios.

Ainda sob a ótica das características centrais ou componentes dos indicadores de acessibilidade, Raia Jr (2000) apresenta uma proposta abrangente de classificação, dividindoos em cinco tipos distintos. O indicador tipo atributos de redes é aquele no qual a conectividade entre determinados pontos de uma rede é o principal elemento observado, atribuindo-se valores a essa conectividade ou separação espacial. Um segundo tipo é o de quantidade de viagens, que está associado a aspectos do comportamento de viagem que dependem do custo dessas viagens e/ou da atratividade de determinadas localidades.

O tipo oferta do sistema de transporte é o terceiro tipo e trata de elementos relacionados à oferta de transportes como os assentos ofertados, a frequiência do sistema de transporte, o número de rotas e etc.

O quarto e quinto tipos são aqueles que combinam aspectos de transportes e de uso do solo de forma agregada e aqueles que utilizam esses mesmos elementos, porém, de forma desagregada, respectivamente.

Segundo Cardoso (2008), os índices de acessibilidade utilizados em modelos de transporte são baseados na premissa de que a separação, seja ela por meio do tempo, da distância ou mesmo custo, limita o número de oportunidades disponíveis aos indivíduos. Parte desses indicadores trata primordialmente da separação espacial entre origem e destino, seguindo a linha de raciocínio desenvolvida por Shimbel em 1953, enquanto outros incorporam também fatores 
relativos às atividades urbanas, dando sequência ao desenvolvimento de Hansen em 1959. Estes indicadores são frequentemente utilizados pela sua simplicidade e robustez, mas alcançando resultados similares aos de outros de formulação mais sofisticada (Pires, 2000).

A separação espacial reflete a facilidade de viagem entre os diferentes pontos do espaço e essa facilidade é determinada pelas características e pela qualidade do serviço fornecido pelo sistema de transportes. Por outro lado, o fator relativo às atividades pode ser caracterizado pela localização, capacidade, quantidade ou por aspectos qualitativos das unidades prestadoras de serviço, ou seja, a atratividade de uma determinada localidade, conforme indica Almeida (1999).

Dessa forma, é possível perceber-se que o uso dos indicadores de acessibilidade, mesmo os menos complexos, contribui para a obtenção de informações sobre os níveis de exclusão espacial enfrentados pelas diversas localidades, seja em função das características da rede de transportes, seja pelas atividades nelas desenvolvidas. E, a partir daí, transformações na realidade local podem ser promovidas em sintonia com o interesse público e respeitando o princípio da equidade e inclusão social.

\section{Descrição do Procedimento}

O procedimento busca obter resultados, segundo uma concepção ampla e relacionada com o desenvolvimento integrado e a minimização das desigualdades, que contribuirão para a identificação, hierarquização e a seleção das possíveis alternativas de investimentos mais adequadas para o setor. $\mathrm{O}$ procedimento proposto contempla características e especificidades locais e segue uma estrutura sistematizada, como mostra a Figura 1, a seguir.

1) A primeira etapa consistiu em identificar e caracterizar as vinte áreas que incluem as capitais e outros municípios com alguma importância econômica na região que tiveram como critério a disponibilidade de informações, conforme estabelecido por Pires Jr. et al (2003). A caracterização destas áreas foi feita em relação à infraestrutura de transportes e à qualidade operacional do sistema hidroviário. Foram analisados também dados socioeconômicos, como: a população e os tipos de atividades socioeconômicas por município. 


\section{1) Identificação e Caracterização da Área de Estudo}<smiles>C[C@@H]1CC[C@H]2CCC1C2</smiles>

2) Seleção dos Indicadores<smiles>C1CC2CCC12</smiles>

3) Cálculo dos Indicadores<smiles>C1CCCC1</smiles>

4) Análise dos Resultados<smiles>C1CC2CCC1C2</smiles>

5) Conclusões

\section{Figura 1 - Estrutura do procedimento}

2) A segunda etapa consistiu em formular a concepção e os indicadores a serem utilizados na definição dos padrões de acessibilidade dos municípios servidos pelo sistema hidroviário troncal para o transporte particularmente de passageiros. Nesse sentido, pressupõe-se que a infraestrutura de transportes determina, em função de sua configuração, relações com as características físicas e operacionais específicas da região que interagem entre si. Estas interações foram estabelecidas e representadas através de apropriadas medidas para o nível de análise espacial, aqui denominado como local, ou seja, entre os municípios ligados pelas linhas hidroviárias troncais dentro da Região Amazônica.

O estudo da acessibilidade se desenvolveu, nesta etapa, com a aplicação de indicadores de infraestrutura que são baseados unicamente no inverso do somatório das impedâncias e podem ser expressos por:

a) distâncias entre os centróides por hidrovia, o que pode indicar a posição de cada um deles em relação aos demais considerando o acesso hidroviário;

b) tempos de viagens (que tendem a ser menor no sentido de descida do Rio) entre os centróides por hidrovia, o que pode indicar a posição de cada um deles em relação aos demais, considerando o acesso hidroviário e o estado da infraestrutura; 
c) tarifas (que tendem também a ser menor no sentido de descida do Rio) entre os centróides que compõem as linhas hidroviárias, o que pode indicar a posição de cada linha em relação às demais, considerando a dimensão financeira.

3) A terceira etapa consistiu em efetuar os cálculos de acessibilidade, sendo que inicialmente foram contemplados indicadores associados à impedância e depois foi incluída a população para expressar a dimensão socioeconômica. Os cálculos foram estabelecidos a partir de uma matriz considerando os valores de distância, tarifa e tempo entre municípios, e de outra matriz ponderando esses mesmos valores com a população de cada município. Foi utilizada a equação 1 nas duas matrizes, em uma a aplicação da fórmula com inversão das impedâncias e na outra ponderando-se a população com os fatores de impedância para expressar a concepção mais simples de acessibilidade, ou seja, a dimensão que envolve a acessibilidade com base na infraestrutura de transportes:

$$
\begin{aligned}
& \mathrm{Ai}=\sum\left(1 / \mathrm{I}_{\mathrm{ij}}{ }^{\gamma}\right) \\
& \mathrm{j}=1 \mathrm{a} \mathrm{n}
\end{aligned}
$$

Onde:

Ai - acessibilidade da Região i;

$I_{i j}$ - impedância entre a Região i e as demais Regiões j, expressa pelas distâncias, tempos ou tarifas das linhas hidroviárias;

$\gamma_{\text {- fator de calibração; }}$

n - número de áreas que constituem o território em estudo.

Quanto maiores os valores obtidos, melhores condições de acessibilidade de um dado município em relação à distância, ao tempo e tarifa.

Os valores encontrados foram normalizados e relacionados a uma escala, conforme proposição de Silva (1995), em que se considera o desvio padrão de cada intervalo para se construir as classes, que se constituíram de cinco categorias de acessibilidade: excelente, boa, regular, ruim ou péssima. Adotou-se esta proposição, pois o critério aplicado no 
estabelecimento das classes de acessibilidade considerou a distribuição normal de valores e tem sido utilizado com sucesso em outras pesquisas (Pires, 2000) de avaliação dos padrões de acessibilidade em redes rodoviárias. Após esta classificação, os municípios foram analisados quanto a sua localização, verificando-se como se enquadram: em posição de exclusão (ou periferia), de inclusão (ou central) ou intermediária.

Nesta classificação, é utilizado o valor da média $(\mu)$ e seu desvio padrão $(\delta)$ para a análise de consistência dos dados. A Tabela 2 apresenta a definição dos limites das classes de acessibilidade.

Tabela 2 - Limites das classes de acessibilidade ${ }^{3}$

\begin{tabular}{ll}
\hline \multicolumn{1}{c}{ Intervalos dos resultados } & \multicolumn{1}{c}{ Classes } \\
\hline$>\mu+1,282 \delta$ & Áreas de acessibilidade excelente \\
Entre $\mu+0,675 \delta$ e $\mu+1,282 \delta$ & Áreas com acessibilidade boa \\
Entre $\mu$ e $\mu+0,675 \delta$ & Áreas com acessibilidade regular \\
Entre $\mu$ e $\mu-0,675 \delta$ & Áreas com acessibilidade ruim \\
$<\mu-0,675 \delta$ & Áreas com acessibilidade péssima \\
\hline
\end{tabular}

Os dados obtidos nas bases cartográficas foram os de infraestrutura, como extensão das hidrovias, localização dos pontos de ligação das linhas hidroviárias troncais que representaram as sedes para o estudo de acessibilidade, os trechos onde se têm ligação com rodovias, ferrovias e aeroportos; os trechos não navegáveis, e a localização de terminais. As distâncias entre os municípios (centróides) foram extraídas destas bases cartográficas, mas os valores de tarifa e de tempo de viagem foram adotados da pesquisa Rodway realizada pelo grupo PENO (Pires Jr. et al, 2003) na Região Amazônica. Observou-se que na pesquisa Rodway havia apenas oito linhas hidroviárias (Belém - Porto Velho, Macapá - Manaus, Macapá - Porto Velho, Manaus - Macapá, Santarém - Porto Velho, Porto Velho - Belém, Porto Velho - Macapá e Porto Velho - Santarém) interligando apenas cinco municípios entre si. Dessa forma, foi necessário, estabelecer linhas complementares, acrescentando-se a

\footnotetext{
${ }^{3}$ Fonte: elaboração própria.
} 
algumas das linhas existentes duas ou três viagens para se chegar ao destino desejado e avaliar-se os padrões de acessibilidade.

Devido à complexidade desse levantamento para tratar as impedâncias tempo e tarifa, optouse por priorizar na análise, com base nessas premissas, apenas as 5 localidades com ligação hidroviária troncal. A partir daí, foi possível preencher os campos das matrizes de acessibilidade e dar prosseguimento aos cálculos de tempo e também tarifa. Foram considerados apenas os tempos em trânsito de um terminal a outro, não incluindo o tempo de espera entre as linhas. $\mathrm{O}$ valor das tarifas também foi o somatório dos valores das tarifas das linhas intermediárias até o destino final, possibilitando construir a matriz entre os cinco municípios servidos por linhas hidroviárias.

4) A quarta etapa consistiu em analisar os resultados e apresentar as condições de acessibilidade das áreas. Nesta análise, foram comparados os resultados da acessibilidade obtidos nos três indicadores estudados e também um cotejo entre os resultados das matrizes que estudaram apenas os indicadores de infraestrutura e também aquela que incluiu a população. Buscando contribuir na ampliação de dados sobre a análise espacial da Região Amazônica, indicando a posição de cada área de estudo em relação à acessibilidade.

No desenvolvimento das etapas da pesquisa percebeu-se a dificuldade de aplicação das medidas selecionadas de forma abrangente para as 20 localidades selecionadas a princípio, devido a características relativas a ligações hidroviárias troncais ou não entre as localidades. Para 15 localidades tornou-se mais exequiível o uso do fator distância apenas. Essa é uma limitação da pesquisa, na medida em que a dificuldade de acesso a informações precisas e detalhadas inviabiliza a ampla utilização de determinadas medidas de análise.

Nesse sentido, novas oportunidades de pesquisa que possam ampliar esse debate são vistas como promissoras, levantando-se outras medidas de acessibilidade que possam ser utilizadas para o caso da Região Amazônica. Dentre as medidas sugeridas estão aquelas relativas à segurança e ao conforto que os passageiros dispõem nas embarcações assim como as condições físicas de acesso as mesmas, configurando-se como aspectos qualitativos. Medidas quantitativas poderiam ser incluídas também, como o tempo total gasto com o deslocamento, desde a espera da embarcação, passando pelo tempo dentro da embarcação, até a chegada ao 
local de destino, considerando o uso de outros modais para completar o percurso (motorizados ou não).

5) A quinta etapa consistiu em apresentar um panorama preliminar da acessibilidade local da Região Amazônica ampliando sua caracterização, de modo a propiciar a seleção mais adequada de possíveis alternativas de investimentos para o setor e contribuir para o desenvolvimento integrado e a minimização das desigualdades regionais.

Essa ampliação da caracterização da acessibilidade da Região Amazônica é extremamente relevante por indicar a facilidade de deslocamento para alcançar as atividades socioeconômicas de interesse e, é influenciada pela infraestrutura de transportes e/ou pela localização das atividades socioeconômicas.

Observa-se a relação entre a acessibilidade e o desenvolvimento regional à medida que as regiões com melhor acesso para a entrada e saída de materiais, serviços e mercados deverão ser mais produtivas, competitivas e assim melhor sucedidas que as regiões mais distantes e isoladas. Ter essa informação no tocante a acessibilidade permite que se aprimore as condições produtivas e competitivas das localidades mal atendidas pelo serviço de transporte a partir do aporte de investimentos.

Segundo Portugal (2008), a acessibilidade fornecida pela infraestrutura deve ser seletiva e derivada de um projeto de desenvolvimento que deverá estabelecer áreas de interesse para o estímulo ou restrição da acessibilidade. Nesse aspecto, apesar das limitações enfrentadas no decorrer da pesquisa, pode-se perceber, inicialmente, a posição de destaque assumida por Manaus, apresentando um padrão de acessibilidade superior aos outros municípios tanto com relação à distância como com relação ao fator tempo e ao fator tarifa na comparação com todas as outras 16 localidades pesquisadas. O que indica que Manaus, pela sua importância econômica, deve manter as condições apresentadas, mas as outras localidades precisam ser priorizadas na ampliação das condições de deslocamento dos passageiros. 


\section{Análise dos Resultados}

Os cálculos dos indicadores de distância foram realizados a partir de uma matriz que relaciona cada um dos vinte municípios estudados. Para o cálculo dos indicadores de tempo e tarifa, foram considerados apenas os cinco municípios que pertencem às linhas hidroviárias troncais.

Os municípios de Manaus, Itacoatiara e Parintins foram classificados como tendo acessibilidade excelente. Estes municípios estão em posição mais centralizada entre os municípios que compõem as linhas troncais do sistema hidroviário. Manaus obteve a melhor classificação dentre os vinte municípios considerados no estudo. Os municípios que estão a distâncias menores de Manaus apresentam excelente ou boa acessibilidade. A Tabela 3 mostra os níveis de acessibilidade dos municípios em relação ao indicador distância.

Tabela 3 - Padrões de Acessibilidade do Indicador Distância ${ }^{4}$

\begin{tabular}{cl}
\hline Classes de Acessibilidade & \multicolumn{1}{c}{ Localidades } \\
\hline Excelente & Manaus, Itacoatiara e Parintins \\
Boa & Coari, Santarém e Tefé \\
Regular & Caracaraí, Itaituba e Vitória do Jaraí \\
Ruim & Humaitá, Porto Velho, Macapá, Boa \\
& Vista, Belém e São Gabriel da Cachoeira \\
Péssima & Tabatinga, Cruzeiro do Sul, Boca do \\
& Acre, Eirunepé e Rio Branco \\
\hline
\end{tabular}

Observou-se que à medida que os municípios se distanciam de Manaus, a acessibilidade se torna pior. Coari, Santarém e Tefé ocuparam a classificação boa; já Caracaraí, Itaituba e Vitória do Jarí foram classificados com acessibilidade regular, sendo que os dois primeiros estão localizados nos afluentes do rio Amazonas (rio Branco e rio Tapajó), e o terceiro está localizado no rio Jarí, no município do Amapá.

Humaitá e Porto Velho localizam-se no rio Madeira em uma posição mais periférica em relação ao conjunto de municípios das linhas troncais. Enquanto Macapá e Boa Vista estão na

\footnotetext{
${ }^{4}$ Fonte: elaboração própria.
} 
região periférica ao norte. Belém e São Gabriel da Cachoeira estão localizados nas regiões periféricas leste e oeste respectivamente. Todos estes ficaram classificados com acessibilidade ruim.

Os níveis de acessibilidade relacionados ao indicador tempo foram os seguintes: Manaus foi o único município a ser classificado como tendo acessibilidade excelente e não houve municípios classificados com acessibilidade boa ou regular. Macapá, Santarém e Belém se classificaram como ruim e Porto Velho como péssimo. Com relação ao indicador tarifa, se verificaram os mesmos resultados. A Tabela 4 mostra os resultados dos três indicadores para os cinco municípios que fazem ligação das linhas hidroviárias troncais.

Verificou-se que os municípios Manaus, Macapá e Belém tiveram, para os três indicadores, a mesma classificação. O indicador distância retratou as condições físicas existentes na região. Já os indicadores de tempo e tarifa consideraram as linhas hidroviárias disponíveis que não fazem ligação direta entre os cinco municípios, sendo utilizadas as estimativas de tempo e tarifa que podem ter alterado as classificações dos municípios de Santarém e Porto Velho.

Ainda considerando os dados apresentados na Tabela 4, como o valor da tarifa tende a ser proporcional ao tempo de viagem, a classificação da acessibilidade foi a mesma para ambos os indicadores.

Observou-se também que, para o indicador tempo, Macapá, Santarém e Belém ocuparam respectivamente o segundo, terceiro e quarto lugares, enquanto que, para o indicador tarifa, estavam nestas posições Santarém, Belém e Macapá. Notou-se também que Manaus manteve a mesma classificação - excelente - para os três indicadores e primeira colocação entre os municípios.

Ainda foram novamente calculados os indicadores de acessibilidade incorporando a população de cada município, de modo a considerar a importância relativa que esta variável pode representar. Em cada célula da matriz para um determinado município de origem ponderou-se a população do município destino pela distância entre origem e destino, o mesmo foi feito para o tempo e a tarifa. 
Tabela 4 - Acessibilidade segundo indicadores de distância, tempo e tarifa ${ }^{5}$

\begin{tabular}{lcccccc}
\hline \multirow{2}{*}{ Municípios } & \multicolumn{3}{c}{ Valores de Acessibilidade } & \multicolumn{3}{c}{ Classes } \\
\cline { 2 - 7 } & Distância & Tempo & Tarifa & Distância & Tempo & Tarifa \\
\hline Manaus & 4,0302 & 3,4843 & 2,4098 & Excelente & Excelente & Excelente \\
Santarém & 3,2355 & 2,5316 & 1,7345 & Boa & Ruim & Ruim \\
Macapá & 2,5500 & 2,5773 & 1,6023 & Ruim & Ruim & Ruim \\
Porto Velho & 2,3426 & 2,0876 & 1,4103 & Ruim & Péssima & Péssima \\
Belém & 2,2421 & 2,3923 & 1,7280 & Ruim & Ruim & Ruim \\
\hline
\end{tabular}

As matrizes que incluíram a população foram calculadas inicialmente sem o preenchimento da diagonal zero. Como resultado, observou-se que as cidades mais populosas ficaram mal posicionadas, como Belém e Manaus, que se classificaram respectivamente como regular e ruim, favorecendo a colocação de municípios menos populosos. Adotou-se então o procedimento de incluir valores a cada fator de impedância a fim deles melhor representarem o que se esperava da realidade. Para o fator distância, foram utilizados valores da população ponderada pela distância entre o centro e o limite do município. Esse valor foi calculado através da área territorial da base SIDRA (IBGE, 2000). Para o fator tempo, as células foram preenchidas com a população da cidade ponderada pelo tempo percorrido entre o centro do município até seu limite. Esse valor de tempo foi calculado através da velocidade média de deslocamento com informações sobre tempo e distância das linhas hidroviárias fornecidas pela pesquisa Rodway (Pires Jr. et al, 2003). Para o fator tarifa, as células foram preenchidas com a população do município ponderada pela tarifa cobrada pelo deslocamento do centro do município até seu limite. Esse valor da tarifa foi calculado pela tarifa média por quilômetro multiplicada pela distância dos trechos de cada município correspondente.

Verificou-se que mesmo utilizando esse procedimento, os resultados apresentados divergiram muito em relação às matrizes que não incluíram a população, principalmente quanto ao município Belém. A sua classificação passou de acessibilidade ruim (quando consideraram

\footnotetext{
${ }^{5}$ Fonte: elaboração própria.
} 
apenas as impedâncias) para acessibilidade excelente (quando a população foi incluída). Em termos de população, Belém só é superada por Manaus por pouca diferença. Mas por outro lado, observou-se, que em termos de distâncias entre os centros e os limites desses municípios há grande diferença, sendo que Manaus apresenta distância muito maior para que Belém. Por isso, ao se ponderar a população pela distância, Belém ficou em primeira colocação seguido por Manaus. Talvez isto ressalte a importância da dimensão socioeconômica na determinação da acessibilidade.

\section{Conclusão}

O presente estudo se propôs a estudar os padrões de acessibilidade existentes em determinadas localidades da Região Amazônica, segundo uma concepção abrangente e comprometida com o desenvolvimento integrado e a minimização das desigualdades, pois entende-se que o levantamento das condições de acessibilidade torna possível a identificação, hierarquização e a seleção das alternativas de investimentos mais adequadas para o setor de transportes. E, que, consequentemente, a realização dessas melhores alternativas viabilizam o aprimoramento das condições de deslocamento para a população residente nas localidades, até então, menos atendidas pelo sistema de transportes. Ou seja, cria-se condições para a inserção dessas pessoas na dinâmica econômica e social vigente.

A classificação de cada município por nível de acessibilidade pode ser muito útil para estudos de desenvolvimento da Região, de modo a indicar o retrato da situação atual dos municípios. De acordo com os planos de desenvolvimento sustentáveis, será importante estabelecer áreas que precisam favorecer a acessibilidade e outras que precisam ser restringidas. Portanto, este trabalho pode oferecer dados importantes para uma primeira análise espacial da Região.

A partir dessa análise espacial, criar compatibilidade entre oferta e a demanda de transportes pode significar inclusão social. Por isso, o transporte pode ser considerado um dos elos fundamentais da vida em sociedade, viabilizando a realização de deslocamentos para os mais diversos fins, impactando diretamente sobre os usuários do sistema e indiretamente, sobre a sociedade como um todo. 
A relevância da escolha de alternativas mais adequadas de investimento está associada não só à importância do uso racional dos recursos públicos e/ou privados, mas também à grande representatividade do transporte fluvial anual de passageiros na Região Amazônica.

A pesquisa privilegiou a análise espacial da oferta de transportes e da acessibilidade por ela gerada em função das impedâncias existentes - distância, tempo de percurso, tarifas - entre as diferentes áreas do território Amazônico. Nesse sentido, o procedimento adotado incluiu a seleção dos indicadores mais apropriados; o cálculo desses mesmos indicadores para cada município; a classificação de cada um segundo os padrões de acessibilidade encontrados; e, finalmente a análise dos resultados, determinando-se o grau de integração ou desarticulação existente entre as áreas que constituem a Região Amazônica, destacando-se aquelas que se encontram em condições mais críticas.

Na etapa de classificação das localidades segundo os padrões de acessibilidade encontrados, pode-se evidenciar que não há uma configuração equitativa da região estudada, havendo melhores condições de deslocamento para as localidades mais próximas à Manaus, enquanto as localidades mais distantes enfrentam maiores obstáculos para a realização de deslocamentos diversos, evidenciando-se nesses casos maior necessidade de intervenção do poder público através de investimentos de infraestrutura.

O estudo de acessibilidade na região Amazônica através dos indicadores de infraestrutura contribuiu para estabelecer não só o nível de acessibilidade entre os municípios estudados, mas também demonstrou o grau de centralidade dos mesmos. Observou-se também que a inclusão da população como forma de considerar a dimensão socioeconômica revelou resultados diferentes, o que indica a sua importância bem como a necessidade de melhor calibrá-la com os fatores de distância, tempo e tarifa.

Quanto ao indicador distância, verificou-se que os municípios que ocuparam as seis primeiras posições se encontram naturalmente em posições mais centralizadas no mapa da Região Amazônica, sendo que Manaus, Itacoatiara e Parintins foram classificados como excelentes; e Coari, Santarém e Tefé se classificaram com boa acessibilidade. Os demais municípios passaram a uma posição mais periférica, apesar de que Caracaraí, Itaituba e Vitória do Jari se classificaram com acessibilidade regular estarem em posição pouco afastada do centro. 
Quanto aos indicadores de tempo e tarifa, houve alteração na ordem de posição, apesar de os cinco municípios apresentarem a mesma classificação de acessibilidade.

Sugere-se incluir alguns ajustes à aplicação destes cálculos, como: as características de navegabilidade na determinação da acessibilidade, outras variáveis para melhor expressar a dimensão socioeconômica e também a necessidade de melhor investigar os padrões de acessibilidade para calibrar os pesos mais compatíveis com a realidade das impedâncias e população.

Nesse sentido, novas oportunidades de pesquisa que possam ampliar esse debate são vistas como promissoras, levantando-se também outras medidas de acessibilidade que possam ser utilizadas para o caso da Região Amazônica, como forma de aprimorar esse estudo inicial. Dentre as medidas sugeridas estão aquelas relativas à segurança e ao conforto que os passageiros dispõem nas embarcações assim como as condições físicas de acesso as mesmas, configurando-se como aspectos qualitativos. Medidas quantitativas poderiam ser incluídas também, como o tempo total gasto com o deslocamento, desde a espera da embarcação, passando pelo tempo dentro da embarcação, até a chegada ao local de destino, considerando o uso de outros modais para completar o percurso (motorizados ou não).

\section{Referências}

Almeida, L. M. W. (1999) Desenvolvimento de uma metodologia para análise locacional de sistemas educacionais usando modelos de interação espacial e indicadores de acessibilidade. Tese (Doutorado em Engenharia de Produção), Universidade Federal de Santa Catarina, Santa Catarina.

Alves, L. E. S. (2007) O transporte hidroviário regular e turístico de passageiros. Seminário Internacional sobre Hidrovias. Brasil / Frandres - Bélgica. Ministério dos Transportes/ Agência Nacional de Transporte Aquaviário.

Agência Nacional das Águas - ANA (2005) A navegação interior e sua interface com o setor de Recursos Hídricos. Cadernos de Recursos Hídricos. Disponível em: www.ana.gov.br.

Andrade, A. A. e Pereira, L. e Andrade, R. A. (2003) Transporte hidroviário. Revista dos Transportes Públicos, n. 100, ano 25.

Bertolini, L., Le Clercq, F. e Kapoen, L. (2005) Sustainable accessibility: a conceptual framework to integrate transport and land use plan-making. Two test-applications in the Netherlands and a reflection on the way forward. Transport Policy, vol. 12, n. 3, pp. 207-220.

Calheiros, C. S. (2010) Metodologia de tarifa para transporte fluvial de passageiros na Amazônia. Tese (Doutorado em Engenharia de Transportes), Universidade Federal do Rio de Janeiro, Rio de Janeiro. 
Cardoso, C. E. P. (2008) Análise do transporte coletivo urbano sob a ótica dos riscos e carências sociais. Tese (Doutorado em Serviço Social), Pontifícia Universidade Católica de São Paulo, São Paulo.

Cardoso, L. (2007) Transporte público, acessibilidade urbana e desigualdades socioespaciais na região metropolitana de Belo Horizonte. Tese (Doutorado em Geografia), Universidade Federal de Minas Gerais, Belo Horizonte.

Delbosc, A. e Currie, G. (2010) Transport problems that matter - social and psychological links to transport disadvantage. Journal of Transport Geography, vol. 19, n. 1, pp.170-178.

Geurs, K. T. e Wee, B. (2004) Accessibility evaluation of land-use and transport strategies: review and research directions. Journal of Transport Geography, vol. 12, n. 2, pp.127-140.

Godoy, P. R. C. e Vieira, A. P. (2004) Hidrovias interiores. Ministério dos Transportes do Brasil. Departamento de Vias Navegáveis. Brasília, Brasil.

Halden, D. (2002) Using accessibility measures to integrate land use and transport policy in Edinburgh and the Lothians. Transport Policy, vol. 9, n. 4, pp. 313-324.

IBGE (2007). Consulta da área territorial e da população. Disponível em: www.ibge.gov.br/home/geociencias/areaterritorial/area.shtm; Data da consulta: 19/06/2007.

Luis, J. A. H. (2002) Temporal accessibility in archipelagos: inter-island shipping in the Canary Islands. Journal of Transport Geography, vol. 10, n. 3, pp.231-239.

Neves, C. (s.d.) A ligação hidroviária Barra-Centro. Disponível em www.fnttaa.org.br/ligbarracentro.html. Data da Consulta: 02/06/2010.

Pires, F. M. A. (2000) Uma contribuição para análise dos padrões de acessibilidade em redes rodoviárias. Dissertação (Mestrado em Engenharia de Transportes) Universidade Federal do Rio de Janeiro, Rio de Janeiro.

Pires Jr., F. C. M., Assis, L. F., Silva Jr., J. A. F. da., Antoun, A. R., Pereira, F. de S. e Souza, C. M. (2003) Transporte fluvial de passageiros na Amazônia: regulamentação do setor e segurança da navegação. Segundo Relatório Intermediário de Pesquisa Roadway. Rio de Janeiro: PENO/COPPE/UFRJ.

Plano de Desenvolvimento Sustentável da Amazônia Legal (2006) Estudos diagnósticos setoriais PDSA 2005-2008. Ministério da Integração Nacional. Belém: ADA.

Portugal, L. S. (2008) A Infraestrutura de transportes e sua relação com o desenvolvimento sustentável na Amazônia. Seminário Infraestructuras en la Amazonía. Reunión del Banco Interamericano de Desarrollo para orientar acciones futuras en la Región. INTAL- Instituto para a Integração da América Latina e do Caribe. Banco Interamericano de Desenvolvimento. CEBRI, Rio de Janeiro, Brasil. www.iadb.org

Preston, J. e Rajé, F. (2007) Accessibility, mobility and transport-related social exclusion. Journal of Transport Geography. vol. 15, n. 3, pp.151-160.

Raia Jr., A. A. (2000) Acessibilidade e mobilidade na estimativa de um índice de potencial de viagens utilizando redes neurais artificiais e sistemas de informação geográfica. Tese (Doutorado em Engenharia de Transportes), Universidade de São Paulo, São Carlos.

Schneider, N. C. B. G. (2000) Hidrovias interiores: um modal econômico e ambientalmente viável? Dissertação (Mestrado em Gestão Econômica do Meio Ambiente), Universidade de Brasília, Brasília.

Silva, W. P. (1995) Contribuição metodológica para o planejamento de um sistema viário. Dissertação (Mestrado em Engenharia de Transportes), Universidade Federal do Rio de Janeiro, Rio de Janeiro. 
Sistema IBGE de Recuperação Automática - SIDRA (2000) Áreas territoriais. Disponível em: www.sidra.ibge.gov.br/bda/tabela/listabl.asp. Data da consulta: 19/06/2007.

Souza, M. H. (2009) Contribuição metodológica para localizar terminal de integração de passageiros do transporte hidro-rodoviário urbano. Tese (Doutorado em Engenharia de Transportes), Universidade Federal do Rio de Janeiro, Rio de Janeiro. 